the accumulation of active metabolites; and an interaction between dihydrocodeine and endogenous opiate-like peptides. Levine ${ }^{3}$ described an increased narcotic effect of codeine phosphate associated with hypocalcaemia in renal failure; our patient, however, remained normocalcaemic. The convulsions might possibly have been due to toxic dihydrocodeine concentrations, ${ }^{4}$ but hypertensive encephalopathy was a more likely explanation in the present case.

In conclusion we urge caution in prescribing dihydrocodeine in conventional dosage to patients with severely impaired renal function.

We are grateful to the poisons unit, New Cross Hospital, London, which measured dihydrocodeine concentrations, and to Dr P A Toseland, Guy's Hospital, for his valuable advice.

1 Peat MA, Sengupta A. Toxicological investigations of cases of death involving codeine and dihydrocodeine. Forensic Science 1977;9:21-32. Weiss B. Dihydrocodeine. A pharmacologic review. American fournal of Pharmacy and the Sciences Supporting Public Health 1959;131:286-301.

${ }^{3}$ I.evine DF. Hypocalcaemia increases the narcotic effect of codeine. Postgrad Med F 1980;56:736-7.

- Eddy NB. Studies of morphine, codeine and their derivatives. 7 Pharmacol Exp Ther 1936;56:421-31.

(Accepted 25 ()ctuber 1982)

The London Hospital, London E1 $1 \mathrm{BB}$

J N BARNES, MA, MRCP, lecturer in medicine, medical unit

F J GOODW IN, MD, FRCP, consultant physician, department of nephrology

\section{Perinatal transmission of hepatitis B in Northern Ireland}

Hepatitis $\mathbf{B}$ infection may be transmitted from the mother to her newborn infant, so that the infant becomes a carrier. The transmission rate varies from 0 to $6 \%$ in Europe and North America ${ }^{1}$ to $40 \%$ in Taiwan. ${ }^{2}$ e Antigen ( $\mathrm{HBeAg}$ ) is associated with a high risk of transmission, ${ }^{2-4}$ and the high prevalence of $\mathrm{HBeAg}$ positive carriers among Chinese and Asian racial groups may account for this difference. The Northern Ireland Blood Transfusion Service routinely tests roughly $98 \%$ of antenatal samples from the region, and screening for hepatitis B surface antigen ( $\mathrm{HBsAg}$ ) has been included since 1973 .

\section{Subjects, methods, and results}

We undertook a retrospective study of women positive for $\mathrm{HBs} \mathrm{Ag}$ and their children using radioimmunoassay (Blood Products Laboratory). The number of births during 1973-81 was 244887 in a total population of 1541987 , the immigrant population forming only a small proportion. All sera positive for HBsAg were referred to the Regional Virus Laboratory for confirmation and from 1981, to the West of Scotland Blood Transfusion Service for marker studies (radioimmunoassay; Abbott) of antibody to hepatitis B core (anti-HBc) and $\mathrm{HBe}$ antigens. Cord blood tests were not possible until 1981, and a child was considered to be positive only if markers persisted after the age of 9 months. The study included all older children in the family when an antenatal sample was $\mathrm{HBs} \mathrm{Ag}$ positive.

Fifty two $\mathrm{HBsAg}$ positive mothers were identified: 34 were white, 16 Oriental, and two African. The table gives the results in children born to 17 of the 34 white mothers. One and possibly two of the white mothers positive for HBeAg had transmitted infection to her child. There was also evidence of transmission in case 3; the woman developed anti-e one year after delivery. $\mathrm{HBe}$ studies were not done in case 4 until after the birth of all the children, and the woman may possibly have been an $\mathrm{HBeAg}$ carrier during her pregnancies.

Carrier state of families of white mothers positive for $\mathrm{HBs} A \mathrm{~g}$ (children positive for $\mathrm{HBs} A \mathrm{~g}$ are described by their $\mathrm{HBe}$ state alone. The two children described as having anti-HBc had no other hepatitis B markers)

\begin{tabular}{cccc}
\hline Case No & eAg & Anti-e & \multicolumn{1}{c}{ Transmission } \\
\hline 1 & + & - & 1 child HBeAg positive \\
2 & + & - & 1 child anti-HBc only at 9 months \\
3 & - & - & 1 child HBeAg positive \\
2 children HBeAg positive \\
1 child anti-HBc positive at 3 years \\
1 child immune \\
2 children no markers \\
No markers among 16 children
\end{tabular}

\section{Comment}

Data from other parts of the UK suggest that, apart from infants of women with acute hepatitis B during the last trimester, newborn white infants are not at risk. All the women studied here had been carriers for several years, and there was no history of acute hepatitis during pregnancy. Our experience indicates that, at least in Northern Ireland, an appreciable number of white children have been infected by their mothers (seven of 25 children studied showed hepatitis B markers).

Reliable tests for $\mathrm{HBe}$ markers have become available only recently; we do not, therefore, have records of $\mathrm{HBe}$ state at the time of the relevant pregnancies in cases 4 and 5 . One of the women positive for anti-HBe had a sister who was also an $\mathrm{HBsAg}$ carrier with anti-HBe. Each had two unaffected children, but the mother of the proposita was $\mathrm{HBsAg}$ and anti-HBe positive. Possibly the mother may have been a carrier of $\mathrm{HBeAg}$ in the past.

Our findings indicate that there is a substantial "high risk" group of white people in some communities, and any discussion of prophylaxis for neonates should not, therefore, exclude them. The presence of $e$ antigen and the absence of all e markers continue to be indicators of a high risk of transmission. All babies born to mothers in either of these categories should be offered prophylaxis. We have initiated a protocol of passive-active immunisation for high risk babies in Northern Ireland and hope to collaborate with regions in Scotland. The protocol includes whites and non-whites.

1 Derso A, Boxall EH, Tarlow MJ, Flewett TH. Transmission of HBsAg from mother to infant in four ethnic groups. $\mathrm{Br}$ Med $\mathcal{F} 1978 ; \mathrm{i}: 949-52$. ${ }^{2}$ Beasley RP, Linn CC, Wang KY, et al. Hepatitis B immune globulin (HBIG) efficacy in the interruption of peri-natal transmission of hepatitis B virus carrier state. Lancet 1981 ;ii:388-93.

${ }^{3}$ Mollica F, Musumeci S, Rugolo S, Mattina T. A prospective study of 18 infants of chronic HBsAg mothers. Arch Dis Child 1979;54:750-4.

4 Wong VCW, Lee AKY, Ip HMH. Transmission of hepatitis B antigens from symptom free carrier mothers to the fetus and the infant. $B r \mathcal{F}$ Obstet Gynaecol 1980;87:958-65.

(Accepted 12 November 1982)

Northern Ireland Blood Transfusion Service, Belfast BT12 4GE CHITRA BHARUCHA, MB, MRCPATH, deputy director D CROWLEY, FIMLS, chief medical laboratory scientific officer M MCCLELLAND, MB, MRCPATH, director

Glasgow and West of Scotland Blood Transfusion Service R J CRAWFORD, MB, MRCPATH, consultant

\section{Gangrenous caecal volvulus after colonoscopy}

Although potentially hazardous, colonoscopy is generally safe with few complications. ${ }^{1}$ Perforation and bleeding are the most common complications, but intramural air dissection, retroperitoneal emphysema, splenic injury, asymptomatic serosal tears and mesenteric haematomas, ileus, partial volvulus of the transverse colon, and incarceration of a hernia have also been reported. ${ }^{1-3}$ We report a case of caecal volvulus after colonoscopy.

\section{Case report}

A 71 year old woman was admitted with a history of weight loss, malaise, bleeding per rectum, and intermittent fever. On examination she was feverish and the colon in the left iliac fossa was tender and palpable. Tests for faecal occult blood were positive on three occasions. Barium enema showed numerous diverticula, particularly in the descending and upper sigmoid colon. Barium was noted outwith the colon at the level of the iliac crest, and in the same area there was a suspicion of an intraluminal mass lesion. She was referred for colonoscopy.

After 48 hours of full routine preparation colonoscopy was carried out with an Olympus TCF type $2 \mathrm{~L} 2$. Fluid faecal residue in the lower colon necessitated frequent aspiration and slow advancement of the instrument, but the splenic flexure was reached without problem. No intraluminal lesion was seen up to this level. Over the next 48 hours she complained of increasingly severe central abdominal colic and abdominal distension developed She was transferred to the surgical unit. Abdominal examination showed 